\title{
Interneurons: Role in Maintaining and Restoring Synaptic Plasticity
}

\author{
Maria Elisa Calcagnotto* \\ Neurophysiology and Neurochemistry of Neuronal Excitability and Synaptic Plasticity Laboratory, Biochemistry Department, \\ Universidade Federal do Rio Grande do Sul, Porto Alegre, Brazil
}

Keywords: GABA, interneurons, synaptic plasticity, brain oscillations, cell replacement

Inhibitory circuits play an important role in synaptic plasticity during development and adulthood. Changes in interneuronal activity induce structural and synaptic rearrangements of inhibitory interneurons, network oscillations, and homeostatic plasticity. In addition to epileptic seizures, deficits in the inhibitory system lead to aberrant information processing and cognitive impairment in various neurological disorders. Studies exploring the structural and functional plasticity of interneurons are essential, not only to understand the mechanisms underlying normal development and behavior but also, to identify the etiology of different psychiatric and neurological disorders to pursue new therapies. Here, it will be discussed the role of inhibitory circuit in the synaptic plasticity, and how cellular replacement strategies can remodel changes in circuit function and homeostasis in the context of brain repair.

\section{INTERNEURON DIVERSITY AND ORIGIN}

OPEN ACCESS

Edited by:

Rochelle S. Cohen,

University of Illinois at Chicago, USA

Reviewed by:

Jean-Claude Lacaille, Université de Montréal, Canada Corette J. Wierenga, Utrecht University, Netherlands

*Correspondence: Maria Elisa Calcagnotto elisa.calcagnotto@ufrgs.br

Specialty section: This article was submitted to Systems Biology, a section of the journal Frontiers in Psychiatry

Received: 01 September 2015 Accepted: 02 May 2016 Published: 12 May 2016

Citation:

Calcagnotto ME (2016) Interneurons: Role in Maintaining and Restoring Synaptic Plasticity.

Front. Psychiatry 7:86. doi: 10.3389/fpsyt.2016.00086
Most of the gamma-aminobutyric acid-containing (GABAergic) interneurons in the cerebral cortex and hippocampus originate from three progenitor regions in the embryonic subpallium: caudal ganglionic eminence (CGE), medial ganglionic eminence (MGE), and preoptic area (POA) (1-4). Each progenitor region produces a particular group of interneurons, although some interneuron classes may emerge from different progenitor domains. In the cortex and in the hippocampus, the MGE produces most of the interneurons including fast spiking-parvalbumin (FS-PV)-expressing basket and chandelier cells and somatostatin (SOM)-expressing interneurons with or without coexpression of calretinin (CR), neuropeptide-Y (NPY), or reelin. CGE generates cholecystokinin (CCK), CR, vasointestinal peptide (VIP), reelin, and neurogliaform cells, but not SOM-expressing interneurons. Some interneurons coexpress CR and VIP, whereas others coexpress NPY and reelin. POA originates a small population of reelin and/or NPY-expressing neurons. Recent studies indicate that this region may also give rise to a small fraction of PV- and SOM-expressing cortical interneurons whose development does not depend on Lhx6 function (3). These inhibitory interneurons play key roles in regulating local circuit activity and synaptic plasticity (5).

\section{INTERNEURONS ORCHESTRATING SYNAPTIC PLASTICITY AND OSCILLATIONS}

In the cortex and hippocampus, interneurons subtypes differ in their functional connectivity and generate differentially timed inhibition at distinct sites of postsynaptic cells (6-8). Interneurons are perfectly positioned to synchronize network activity. Some target dendritic domains (e.g., SOM-, NPY-, or CB-expressing interneurons) to control the efficacy and plasticity of excitatory inputs onto principal neurons (7). In CA1 hippocampal region, the oriens-lacunosum moleculare (O-LM) and bistratified interneurons, both expressing PV and SOM, are dendritic targeting cells (9). Others target perisomatic compartments (i.e., soma, axon initial segment, and thick proximal dendrites) (e.g., FS-PV-expressing basket cells or CCK-expressing interneurons) (6) to control the output 
and consequently synchronize the firing rate of principal cells action potentials (10-12). The hippocampal CA1 pyramidal cells soma receive abundant GABAergic inputs from basket cells (13) that are able to control the ability of inputs to generate action potential and to synchronize the pyramidal neurons firing rate (10). Chandelier cells target the axon initial segments of several pyramidal neurons and also contribute to the output synchronization of CA1 principal cells (14). In the mature cortex, a single basket interneuron is able to form characteristic perisomatic synapses (15) with hundreds of pyramidal neurons (16). Each pyramidal neuron, in its turn, can receive inputs from multiple basket cells $(16,17)$. The postnatal maturation of perisomatic innervation is essential to synchronize pyramidal neurons activity within cortical circuits. In addition to perisomatic inhibition, other FS-PV-expressing interneurons also innervate either axons (chandelier cells) (18) or dendrites (O-LM and bistratified cells) of target cells $(7,9,19,20)$. All these GABAergic inputs in specific subcellular domains play an important role in brain oscillations and plasticity. In particular, the FS-PV-expressing interneurons are known to be crucial in gamma $(30-80 \mathrm{~Hz})$ oscillations in the cortex and hippocampus $(5,21,22)$, involved in cognition and information processing (23). Accordingly, the blockage of synaptic output of hippocampal PV-expressing interneurons impairs spatial working memory (24). Moreover, the O-LM and bistratified cells that fire in phase with theta oscillations generate global dendritic inhibition, mediate network-state-dependent inhibition on specific parts of pyramidal neuron dendrites, are targeted by afferents from the medial septal region, and are crucial for hippocampal rhythm generation in behaving animal $(9,19,20)$. During gamma oscillations, bistratified cells seem to participate in the transmission of the CA3-dependent gamma component to CA1 $(19,20)$.

Besides the direct control of inhibition, synchrony and plasticity on principal cells, different interneuron subtypes exhibit a wide range of responses to different neuromodulatory inputs, leading to changes in net inhibition, synchronization, and synaptic plasticity (25). The innervation pattern of O-LM cells, which includes the excitation by fast cholinergic transmission, the inhibition of distal dendrites, and the disinhibition of proximal dendrites of pyramidal neurons in CA1, enables them to modulate synaptic efficiency and plasticity of entorhinal cortex and CA3 inputs (19).

Interneuron subtypes differ in their functional connectivity to the principal cells in cortex and hippocampus $(6,8)$, providing different functional outcome for action potential generation from principal cells (7). This can be exemplified by an elegant work from Ledri and colleagues, where the rupture of hypersynchronization was achieved, by controlling the activity of large populations of interneurons rather than a single population of PV- or SOM-expressing interneurons in the hippocampus, using optogenetics (12). The inhibition of PV-expressing interneurons target by optogenetics also seems to suppress gamma power, while its stimulation elicited gamma oscillations in downstream pyramidal neurons (22), therefore controlling network oscillation.

As mentioned above, GABAergic interneurons targeting dendritic domains control the efficacy and plasticity of excitatory inputs onto principal neurons. This dendritic remodeling of inhibitory neurons, either in normal or pathological conditions, affects activity-dependent modulation of neuronal connectivity within local circuits (26). Reduction in dendritic ramification and decreased axonal length has been described in interneurons in schizophrenia (27) and animal models of epilepsy (28). However, decrease in density and substantial increase in size, axonal reorganization, and aberrant synaptic connections of remaining and newborn SOM-expressing interneurons were observed in hippocampal CA1 and dentate gyrus of animal models of epilepsy $(29,30)$. This reorganized circuitry synchronizes granule cells activity and decreases seizure threshold, despite the increment in number of GABAergic terminals, contributing to the inhibitory dysfunction in epilepsy. It seems to be an abundant but dysfunctional attempt to compensate the decreased inhibitory input to granule cells after epileptogenic injuries $(29,30)$. Thus, changes in the synaptic reorganization of SOM-expressing interneurons can disrupt network organization and increase excitation levels.

Together with the interneuronal network connectivity at different cell domains, modulatory inputs and dendritic remodeling, the intrinsic properties of interneurons are particularly crucial to generate and control neuronal oscillations and plasticity (31). For example, the intrinsic properties of FS-PV-expressing interneurons and fast $\mathrm{GABA}_{\mathrm{A}}$ receptor kinetics are likely to be needed to achieve precise timing gamma oscillations in cortex and hippocampus $(21,22)$. Additionally, different GABAergic interneuron subtypes fire independently and innervate distinct postsynaptic domains at different time points. These coordinated synaptic interactions actively orchestrate the precise input/output information to generate and control neuronal activity during network oscillations in different developmental and behavioral states (8).

\section{INTERNEURON REPLACEMENT RESTORES SYNAPTIC PLASTICITY AND NETWORK OSCILLATION}

As we discussed earlier, GABA transmission has an important role in synaptic plasticity. Moreover, it is essential to regulate plasticity during critical periods of brain development. Changes in inhibition create an environment with aberrant neuronal network that is associated with neurodevelopmental (29, 30, 32-35). Interestingly, some of the most consistent findings in autism spectrum disorders, schizophrenia, epilepsy, and cognitive disorders consist in SOM- and PV-expressing interneurons dysfunction in the brain, including O-LM cells (29, 30, 36-39). Thus, by controlling GABAergic activity, it could be possible to maintain or rescue normal network oscillations and synaptic plasticity.

To address this issue, cell replacement using MGE precursors (source of PV- and SOM-expressing interneurons) has been performed in animal models. The studies had shown that MGE-derived cells are able to survive, differentiate in mature interneurons, migrate, and functionally integrate through the host brain parenchyma with low risk of promoting brain tumors. The integrated mature interneurons modify the neuronal network, rescuing the normal functional inhibition and the synaptic plasticity (40-44). Some examples are studies using MGE 
precursors grafted into brain of neonate distal less homeobox 1-deficient mice $\left(D l \times 1^{-1-}\right)$ (34) and cyclin D2 knockout mice $\left(C c n d 2^{-/-}\right)$(43). Dl $x 1^{-/-}$mice exhibit late-onset interneuron loss and reduced inhibition (34), with consequent deficit in interneuronal network, altered gamma frequency oscillations (GFOs), and dysfunction in homeostatic plasticity and seizures (44). The authors demonstrated that MGE-derived cells reduced seizure severity, restored inhibition, normalize gamma oscillations, and reversed the homeostatic changes in excitatory synaptic activity hippocampal long-term potentiation (44). In the Ccnd $2^{-/-}$mice that display deficit in PV-expressing interneurons, hippocampal disinhibition, increased ventral tegmental area dopamine neuronal activity, and cognitive impairment, the MGE-grafted cells were able to differentiate in long-range survival GABAergic interneurons distributed through the hippocampus and reverse the psychosis and cognitive phenotypes (43).

The maturation of GABAergic interneurons, specifically PV-and SOM-expressing subtypes, has been strongly implicated in critical period of plasticity, such as the development of visual cortex $(45,46)$. It has been shown that PV- and SOM-expressing interneurons, derived from MGE-precursors grafted into neonate brain, were able to induce ocular dominance plasticity shortly after the normal critical period. Inhibitory-grafted neurons reorganize the cortical circuitry by introducing a new set of weak inhibitory synapses (47), rather than simply enhancing the endogenous mature inhibitory synaptic strength. This pattern of numerous and weak connections is consistent with the form of developing inhibition during the critical period (48). However, suppression of PV-expressing neurons in visual cortex

\section{REFERENCES}

1. Butt SJ, Fuccillo M, Nery S, Noctor S, Kriegstein A, Corbin JG, et al. The temporal and spatial origins of cortical interneurons predict their physiological subtype. Neuron (2005) 48:591-604. doi:10.1016/j.neuron.2005.09.034

2. Wonders C, Anderson SA. Cortical interneurons and their origins. Neuroscientist (2005) 11:199-205. doi:10.1177/1073858404270968

3. Gelman DM, Marin O. Generation of interneuron diversity in the mouse cerebral cortex. Eur JNeurosci (2010) 31:2136-41. doi:10.1111/j.1460-9568.2010.07267.x

4. Tricoire L, Pelkey KA, Erkkila BE, Jeffries BW, Yuan X, Mcbain CJ. A blueprint for the spatiotemporal origins of mouse hippocampal interneuron diversity. J Neurosci (2011) 31:10948-70. doi:10.1523/JNEUROSCI.0323-11.2011

5. Allen $\mathrm{K}$, Monyer $\mathrm{H}$. Interneuron control of hippocampal oscillations. Curr Opin Neurobiol (2015) 31:81-7. doi:10.1016/j.conb. 2014.08.016

6. Freund TF, Buzsaki G. Interneurons of the hippocampus. Hippocampus (1996) 6:347-470. doi:10.1002/(SICI)1098-1063(1996)6:4<347::AIDHIPO1>3.0.CO;2-I

7. Miles R, Poncer JC. Paired recordings from neurones. Curr Opin Neurobiol (1996) 6:387-94. doi:10.1016/S0959-4388(96)80124-3

8. Klausberger T, Somogyi P. Neuronal diversity and temporal dynamics: the unity of hippocampal circuit operations. Science (2008) 321:53-7. doi:10.1126/ science. 1149381

9. Klausberger T. GABAergic interneurons targeting dendrites of pyramidal cells in the CA1 area of the hippocampus. Eur J Neurosci (2009) 30:947-57. doi:10.1111/j.1460-9568.2009.06913.x

10. Miles R, Toth K, Gulyas AI, Hajos N, Freund TF. Differences between somatic and dendritic inhibition in the hippocampus. Neuron (1996) 16:815-23. doi:10.1016/S0896-6273(00)80101-4

11. Marchionni I, Maccaferri G. Quantitative dynamics and spatial profile of perisomatic GABAergic input during epileptiform synchronization in adult mice also induced plasticity and beyond critical period (49). Therefore, new plasticity can be induced when inhibitory precursors were grafted into visual cortex during development and in adult mice (50-52). The plasticity process seems to be a direct result of modification in neural circuit induced by PV- and SOM-expressing cells integrated into the primary visual cortex. Some suggested mechanism are increased connectivity; increased expression of $\mathrm{GABA}_{\mathrm{A}}$ receptors containing the $\alpha 1$ subunit, abundant at synapses mediated by PV-expressing interneurons (46); and changes in maturation of interneurons $(47,51)$.

Changes in GABAergic function mediated by PV- and SOMexpressing interneurons impair synaptic plasticity and disrupt network organization and normal brain oscillations. However, by temporal and selective coordination of interneuronal activity, it is possible to modulate interneuronal network and increase GABA release on different subcellular domains of target cells to maintain or rescue normal network oscillations and synaptic plasticity. The investigation of $\mathrm{PV}$ - and SOM-expressing interneurons, using strategies that modify interneuronal network and regulate inhibitory input/output of such interneurons at different time points, as selective target them or using precursor cells grafts, are helping us to better understand the role of these specific interneuron subtypes in controlling and restoring synaptic plasticity and brain oscillations during development and adulthood.

\section{AUTHOR CONTRIBUTIONS}

The author confirms being the sole contributor of this work and approved it for publication.

in the CA1 hippocampus. J Physiol (2009) 587:5691-708. doi:10.1113/ jphysiol.2009.179945

12. Ledri M, Madsen MG, Nikitidou L, Kirik D, Kokaia M. Global optogenetic activation of inhibitory interneurons during epileptiform activity. J Neurosci (2014) 34:3364-77. doi:10.1523/JNEUROSCI.2734-13.2014

13. Somogyi P, Klausberger T. Defined types of cortical interneurone structure space and spike timing in the hippocampus. J Physiol (2005) 562:9-26. doi:10.1113/jphysiol.2004.078915

14. Howard A, Tamas G, Soltesz I. Lighting the chandelier: new vistas for axoaxonic cells. Trends Neurosci (2005) 28:310-6. doi:10.1016/j.tins.2005.04.004

15. Wang Y, Gupta A, Toledo-Rodriguez M, Wu CZ, Markram H. Anatomical, physiological, molecular and circuit properties of nest basket cells in the developing somatosensory cortex. Cereb Cortex (2002) 12:395-410. doi:10.1093/ cercor/12.4.395

16. Holmgren C, Harkany T, Svennenfors B, Zilberter Y. Pyramidal cell communication within local networks in layer $2 / 3$ of rat neocortex. J Physiol (2003) 551:139-53. doi:10.1113/jphysiol.2003.044784

17. Somogyi P, Tamas G, Lujan R, Buhl EH. Salient features of synaptic organisation in the cerebral cortex. Brain Res Brain Res Rev (1998) 26:113-35. doi:10.1016/S0165-0173(97)00061-1

18. Kawaguchi Y, Kubota Y. GABAergic cell subtypes and their synaptic connections in rat frontal cortex. Cereb Cortex (1997) 7:476-86. doi:10.1093/ cercor/7.6.476

19. Leao RN, Mikulovic S, Leao KE, Munguba H, Gezelius H, Enjin A, et al. OLM interneurons differentially modulate CA3 and entorhinal inputs to hippocampal CA1 neurons. Nat Neurosci (2012) 15:1524-30. doi:10.1038/nn.3235

20. Muller C, Remy S. Dendritic inhibition mediated by O-LM and bistratified interneurons in the hippocampus. Front Synaptic Neurosci (2014) 6:23. doi:10.3389/fnsyn.2014.00023

21. Cardin JA, Carlen M, Meletis K, Knoblich U, Zhang F, Deisseroth K, et al. Driving fast-spiking cells induces gamma rhythm and controls sensory responses. Nature (2009) 459:663-7. doi:10.1038/nature08002 
22. Sohal VS, Zhang F, Yizhar O, Deisseroth K. Parvalbumin neurons and gamma rhythms enhance cortical circuit performance. Nature (2009) 459:698-702. doi:10.1038/nature07991

23. WomelsdorfT, Schoffelen JM, Oostenveld R, Singer W, Desimone R, Engel AK, et al. Modulation of neuronal interactions through neuronal synchronization. Science (2007) 316:1609-12. doi:10.1126/science.1139597

24. Murray AJ, Sauer JF, Riedel G, Mcclure C, Ansel L, Cheyne L, et al. Parvalbumin-positive CA1 interneurons are required for spatial working but not for reference memory. Nat Neurosci (2011) 14:297-9. doi:10.1038/nn.2751

25. Larkum ME, Nevian T, Sandler M, Polsky A, Schiller J. Synaptic integration in tuft dendrites of layer 5 pyramidal neurons: a new unifying principle. Science (2009) 325:756-60. doi:10.1126/science.1171958

26. Chen JL, Nedivi E. Neuronal structural remodeling: is it all about access? Curr Opin Neurobiol (2010) 20:557-62. doi:10.1016/j.conb.2010.06.002

27. Kalus P, Bondzio J, Federspiel A, Muller TJ, Zuschratter W. Cell-type specific alterations of cortical interneurons in schizophrenic patients. Neuroreport (2002) 13:713-7. doi:10.1097/00001756-200204160-00035

28. Prince DA, Parada I, Scalise K, Graber K, Jin X, Shen F. Epilepsy following cortical injury: cellular and molecular mechanisms as targets for potential prophylaxis. Epilepsia (2009) 50(Suppl 2):30-40. doi:10.1111/j.1528-1167. 2008.02008.x

29. Zhang W, Yamawaki R, Wen X, Uhl J, Diaz J, Prince DA, et al. Surviving hilar somatostatin interneurons enlarge, sprout axons, and form new synapses with granule cells in a mouse model of temporal lobe epilepsy. J Neurosci (2009) 29:14247-56. doi:10.1523/JNEUROSCI.3842-09.2009

30. Peng Z, Zhang N, Wei W, Huang CS, Cetina Y, Otis TS, et al. A reorganized GABAergic circuit in a model of epilepsy: evidence from optogenetic labeling and stimulation of somatostatin interneurons. J Neurosci (2013) 33:14392-405. doi:10.1523/JNEUROSCI.2045-13.2013

31. Chen JL, Nedivi E. Highly specific structural plasticity of inhibitory circuits in the adult neocortex. Neuroscientist (2013) 19:384-93. doi:10.1177/1073858413479824

32. Cossart R, Dinocourt C, Hirsch JC, Merchan-Perez A, De Felipe J, Ben-Ari Y, et al. Dendritic but not somatic GABAergic inhibition is decreased in experimental epilepsy. Nat Neurosci (2001) 4:52-62. doi:10.1038/82900

33. Rubenstein JL, Merzenich MM. Model of autism: increased ratio of excitation/inhibition in key neural systems. Genes Brain Behav (2003) 2:255-67. doi:10.1034/j.1601-183X.2003.00037.x

34. Cobos I, Calcagnotto ME, Vilaythong AJ, Thwin MT, Noebels JL, Baraban SC, et al. Mice lacking Dlx1 show subtype-specific loss of interneurons, reduced inhibition and epilepsy. Nat Neurosci (2005) 8:1059-68. doi:10.1038/nn1499

35. Palop JJ, Chin J, Roberson ED, Wang J, Thwin MT, Bien-Ly N, et al. Aberrant excitatory neuronal activity and compensatory remodeling of inhibitory hippocampal circuits in mouse models of Alzheimer's disease. Neuron (2007) 55:697-711. doi:10.1016/j.neuron.2007.07.025

36. Dugladze T, Vida I, Tort AB, Gross A, Otahal J, Heinemann U, et al. Impaired hippocampal rhythmogenesis in a mouse model of mesial temporal lobe epilepsy. Proc Natl Acad Sci U S A (2007) 104:17530-5. doi:10.1073/ pnas.0708301104

37. Neymotin SA, Lazarewicz MT, Sherif M, Contreras D, Finkel LH, Lytton WW. Ketamine disrupts theta modulation of gamma in a computer model of hippocampus. J Neurosci (2011) 31:11733-43. doi:10.1523/ JNEUROSCI.0501-11.2011

38. Stanley EM, Fadel JR, Mott DD. Interneuron loss reduces dendritic inhibition and GABA release in hippocampus of aged rats. Neurobiol Aging (2012) 33:431.e431-413. doi:10.1016/j.neurobiolaging.2010.12.014
39. Le Magueresse C, Monyer H. GABAergic interneurons shape the functional maturation of the cortex. Neuron (2013) 77:388-405. doi:10.1016/j. neuron.2013.01.011

40. Alvarez-Dolado M, Calcagnotto ME, Karkar KM, Southwell DG, Jones-Davis DM, Estrada RC, et al. Cortical inhibition modified by embryonic neural precursors grafted into the postnatal brain. J Neurosci (2006) 26:7380-9. doi:10.1523/JNEUROSCI.1540-06.2006

41. Zipancic I, Calcagnotto ME, Piquer-Gil M, Mello LE, Alvarez-Dolado M. Transplant of GABAergic precursors restores hippocampal inhibitory function in a mouse model of seizure susceptibility. Cell Transplant (2010) 19:549-64. doi:10.3727/096368910X491383

42. Hunt RF, Girskis KM, Rubenstein JL, Alvarez-Buylla A, Baraban SC. GABA progenitors grafted into the adult epileptic brain control seizures and abnormal behavior. Nat Neurosci (2013) 16:692-7. doi:10.1038/nn.3392

43. Gilani AI, Chohan MO, Inan M, Schobel SA, Chaudhury NH, Paskewitz S, et al. Interneuron precursor transplants in adult hippocampus reverse psychosis-relevant features in a mouse model of hippocampal disinhibition. Proc Natl Acad Sci U S A (2014) 111:7450-5. doi:10.1073/pnas.1316488111

44. Howard MA, Rubenstein JL, Baraban SC. Bidirectional homeostatic plasticity induced by interneuron cell death and transplantation in vivo. Proc Natl Acad Sci U S A (2014) 111:492-7. doi:10.1073/pnas.1307784111

45. Fagiolini M, Hensch TK. Inhibitory threshold for critical-period activation in primary visual cortex. Nature (2000) 404:183-6. doi:10.1038/35004582

46. Fagiolini M, Fritschy JM, Low K, Mohler H, Rudolph U, Hensch TK. Specific GABAA circuits for visual cortical plasticity. Science (2004) 303:1681-3. doi:10.1126/science.1091032

47. Sugiyama S, Di Nardo AA, Aizawa S, Matsuo I, Volovitch M, Prochiantz A, et al. Experience-dependent transfer of Otx2 homeoprotein into the visual cortex activates postnatal plasticity. Cell (2008) 134:508-20. doi:10.1016/j. cell.2008.05.054

48. Gandhi SP, Yanagawa Y, Stryker MP. Delayed plasticity of inhibitory neurons in developing visual cortex. Proc Natl Acad Sci U S A (2008) 105:16797-802. doi:10.1073/pnas.0806159105

49. Kuhlman SJ, Olivas ND, Tring E, Ikrar T, Xu X, Trachtenberg JT. A disinhibitory microcircuit initiates critical-period plasticity in the visual cortex. Nature (2013) 501:543-6. doi:10.1038/nature12485

50. Southwell DG, Froemke RC, Alvarez-Buylla A, Stryker MP, Gandhi SP. Cortical plasticity induced by inhibitory neuron transplantation. Science (2010) 327:1145-8. doi:10.1126/science.1183962

51. Tang Y, Stryker MP, Alvarez-Buylla A, Espinosa JS. Cortical plasticity induced by transplantation of embryonic somatostatin or parvalbumin interneurons. Proc Natl Acad Sci U S A (2014) 111:18339-44. doi:10.1073/pnas.1421844112

52. Davis MF, Figueroa Velez DX, Guevarra RP, Yang MC, Habeeb M, Carathedathu MC, et al. Inhibitory neuron transplantation into adult visual cortex creates a new critical period that rescues impaired vision. Neuron (2015) 86:1055-66. doi:10.1016/j.neuron.2015.03.062

Conflict of Interest Statement: The author declares that the research was conducted in the absence of any commercial or financial relationships that could be construed as a potential conflict of interest.

Copyright (c) 2016 Calcagnotto. This is an open-access article distributed under the terms of the Creative Commons Attribution License (CC BY). The use, distribution or reproduction in other forums is permitted, provided the original author(s) or licensor are credited and that the original publication in this journal is cited, in accordance with accepted academic practice. No use, distribution or reproduction is permitted which does not comply with these terms. 